\title{
A patient-centred approach to health service delivery: improving health outcomes for people with chronic illness
}

\author{
Masoud Mirzaei ${ }^{1,2^{*}}$, Clive Aspin ${ }^{2,7}$, Beverley Essue ${ }^{2,6}$, Yun-Hee Jeon ${ }^{3}$, Paul Dugdale $^{4}$, Tim Usherwood ${ }^{5}$ \\ and Stephen Leeder ${ }^{2}$
}

\begin{abstract}
Background: The Wagner Model provides a framework that can help to facilitate health system transition towards a chronic care oriented model. Drawing on elements of this framework as well as health policy related to patient centred care, we describe the health needs of patients with chronic illness and compare these with services which should ideally be provided by a patient-centred health system. This paper aims to increase understanding of the challenges faced by chronically ill patients and family carers in relation to their experiences with the health care system and health service providers.
\end{abstract}

Method: We interviewed patients, carers and health care professionals (HCPs) about the challenges faced by people living with complicated diabetes, chronic heart failure or chronic obstructive pulmonary disease.

Results: Patients indicated that they had a range of concerns related to the quality of health care encounters with health care professionals (HCPs), with these concerns being expressed as needs or wants. These included: 1) the need for improved communication and information delivery on the part of HCPs; 2) well organised health services and reduced waiting times to see HCPs; 3) help with self care; 4) greater recognition among professionals of the need for holistic and continuing care; and 5) inclusion of patients and carers in the decision making processes.

Conclusions: In order to address the challenges faced by people with chronic illness, health policy must be more closely aligned with the identified needs and wants of people affected by chronic illness than is currently the case.

\section{Background}

Chronic, non-communicable diseases are currently responsible for around $70 \%$ of the total burden of illness and injury experienced by the Australian population and this proportion is expected to increase to almost $80 \%$ by 2020 [1]. According to the most recent burden of disease study in Australia (2003), diabetes, cardiovascular disease and chronic respiratory diseases are the top three conditions responsible for the majority of Disability Adjusted Life Years (DALYs) lost in males. In females, these conditions are among the top seven causes of DALYs lost [2]. Among other things, the aging population and an increase in some risk factors among young

\footnotetext{
* Correspondence: masoud.mirzaei@sydney.edu.au

'Yazd Cardiovascular Research Centre, Shahid Sadoughi University of Medical Sciences, Yazd, Iran

${ }^{2}$ Menzies Centre for Health Policy, University of Sydney, Sydney, Australia Full list of author information is available at the end of the article

of the article
}

population are likely to contribute to increased mortality and morbidity in the near future in developed countries including Australia [3].

In 1999-2000, 17 per cent of hospital admissions were for the chronic illnesses of respiratory and cardiovascular disease, diabetes and cancer. These admissions accounted for 36 per cent of total public hospital bed days. The cost of providing hospital care for people with respiratory and cardiovascular disease, diabetes and cancer, was estimated at $\$ 1.1$ billion in New South Wales (NSW) in 1999-2000 [4].

Wagner has developed a chronic care model to address issues such as these and to facilitate health system transition towards a chronic care oriented model [5-7]. The model identifies patient centeredness, effectiveness, efficiency, equity [7] and timeliness as essential elements of efficient health service delivery for people with chronic illness.

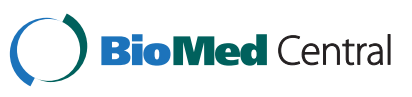


Patient centredness in health care has been shown to increase patient engagement, satisfaction and compliance, improve quality of life and reduce patient anxiety $[8,9]$. Observational studies have demonstrated that patients prefer patient centred care, and those who receive it report enhanced health outcomes [10]. A review by Coulter and Ellins concluded that strategies for informing, educating, attending to needs and wants and involving patients in their chronic care management, all of which are essential ingredients of patient centredness, are effective [11].

Drawing inspiration from the Wagner chronic care model, the Serious and Continuing Illness Policy and Practice Study (SCIPPS) investigated the role of patientcentredness in improving health services for people with chronic illness. SCIPPS is a multi-staged study designed to improve the management and care of people with chronic illness including chronic heart failure (CHF), type 2 diabetes and chronic and obstructive pulmonary disease (COPD) in the Australian Capital Territory (ACT) and NSW. These three index conditions were chosen because they are among the main causes of DALYs lost. As well, they are costly and continuing illnesses that utilise multiple health services, treatments and technologies. Furthermore, a wide spectrum of primary and specialist services, acute and ambulatory care, and community support services, as well as effective self care, is needed for their successful management.

As part of SCIPPS, a qualitative study was undertaken. Patients and carers were interviewed about their experiences of living with the index conditions, including their experiences with the health system and health service providers. Overall findings from the study have been reported elsewhere [12,13].

The aim of this paper is to explore and describe the experiences of patients with chronic illness and their carers, with a particular focus on the challenges that patients confront when interacting with the health system and health service providers.

\section{Methods}

This study used purposive sampling to recruit participants in order to collect data through in-depth interviews and focus groups with patients $(\mathrm{N}=52)$, their carers $(\mathrm{N}=14)$ and health care professionals $(\mathrm{N}=63)$. $^{\mathrm{a}}$ The characteristics of patients and carers summarised in Table 1 and those of HCPs summarised in Table 2 . Participants were recruited from two locations, the Australian Capital Territory (ACT) and Sydney West, New South Wales (NSW).

Based on a preliminary analysis of the patient and carer interviews, problems associated with health service delivery and health care professionals were identified as key issues. This led to a decision to conduct eight focus group discussions (FGDs) with HCPs. During these FGDs, participants were questioned about what they perceived to be the key barriers and facilitators that patients and carers experience while accessing and utilising relevant health services. While the primary focus of the study was on patient experience, it was considered important to recruit a sizeable number of HCPs in order to ensure that the study gathered the full range of diverse experiences related to the chronic illnesses of interest. FGDs were considered to be more appropriate for data collection from HCPs since these allowed them to generate robust discussion. Individual interviews were considered to be most appropriate for patients and carers since it allowed them to talk more freely about issues of a personal nature.

Participants were recruited through referrals from general practices, local hospitals, community health services, specialist clinics, health care consumer organisations, and Aboriginal Medical Services located in Sydney West and ACT. Eligible participants included patients aged between 45 and 85 with one or more of the three index conditions, as well as family care givers and HCPs who have been involved in providing care for people with the index conditions. This age range was chosen because of the high prevalence rates of chronic illness among people of this age. HCPs were recruited from local hospitals, community health services, consumer organisations and Aboriginal medical services in order to represent the broad range of services from which people with chronic illness access services. A sampling grid was used to ensure that participants of varied age, culture, ethnicity, severity of the illness and health care setting, were included. For FGDs, community and hospital nurses, allied health workers, general practitioners and hospital-based staff were included (see Table 2 for details).

Ethical approval to conduct the study was granted by the University of Sydney Human Research Ethics Committee, the Sydney West Area Health Service Human Research Ethics Committee, the Australian National University Human Research Ethics Committee, and the ACT Health Human Research Ethics Committee. All participants provided informed consent and were given the option of stopping the interview or withdrawing from the study at any point if they chose to.

The in-depth, semi- structured interviews were conducted by members of the research team who were also closely involved in the data analysis and writing of manuscripts. Each interview lasted for between 45 and 90 minutes and was followed by a 10-15 minutes interviewers' assisted survey. The survey obtained basic information about the participants such as demographics, health care encounters and the clinical and medication profiles [14]. The survey data were descriptively analysed using SPSS version 13.00 (SPSS Inc; Illinois, USA). 
Table 1 Characteristics of patients and carers

\begin{tabular}{|c|c|c|c|}
\hline Categories & Sub-categories & Patient $(\mathrm{N}=52)$ & ${ }^{\S}$ Carer $(\mathrm{N}=14)$ \\
\hline \multirow[t]{2}{*}{ Residence } & $\mathrm{ACT}$ & $26(50.0 \%)$ & $6(42.9 \%)$ \\
\hline & Sydney West & $26(50.0 \%)$ & $8(57.1 \%)$ \\
\hline \multirow[t]{2}{*}{ Gender } & Male & $28(53.8 \%)$ & $1(07.1 \%)$ \\
\hline & Female & $24(46.2 \%)$ & $13(92.9 \%)$ \\
\hline \multirow[t]{3}{*}{ Age } & Less than 45 yrs & $\wedge 1(1.9 \%)$ & $2(14.3 \%)$ \\
\hline & $45-64$ yrs & $16(30.8 \%)$ & $5(35.7 \%)$ \\
\hline & $65-85$ yrs & $35(67.3 \%)$ & $7(50.0 \%)$ \\
\hline Culturally and linguistically diverse (CALD) & CALD background & $11(21.2 \%)$ & $5(35.7 \%)$ \\
\hline Indigenous & Indigenous background & $7(13.5 \%)$ & 0 \\
\hline Finance & Experiencing financial difficulties & $31(59.6 \%)$ & $11(78.6 \%)$ \\
\hline Marital Status & Married/de facto/living with a partner & $29(55.8 \%)$ & $13(92.9 \%)$ \\
\hline \multirow[t]{2}{*}{ Work Status } & Employed & $5(9.6 \%)$ & $2(14.3 \%)$ \\
\hline & Not employed & $47(90.4 \%)$ & $12(85.7 \%)$ \\
\hline \multirow[t]{6}{*}{ Diagnosis } & Type 2 diabetes & $16(30.8 \%)$ & ${ }^{*} 4(28.6 \%)$ \\
\hline & $\mathrm{CHF}$ & $15(28.8 \%)$ & ${ }^{*} 2(14.3 \%)$ \\
\hline & COPD & $10(19.2 \%)$ & ${ }^{*} 5(35.7 \%)$ \\
\hline & More than one index condition & $11(21.2 \%)$ & ${ }^{*} 3(21.3 \%)$ \\
\hline & Average length of illness & 16.5 years & ${ }^{*} 21.4$ years \\
\hline & Other co-morbid conditions & $43(86.5 \%)$ & ${ }^{*} 11(85.7 \%)$ \\
\hline \multirow[t]{7}{*}{ Visit to GP } & Weekly & $4(7.7 \%)$ & ${ }^{*} 1(7.1 \%)$ \\
\hline & Fortnightly & $8(15.4 \%)$ & ${ }^{*} 6(42.9 \%)$ \\
\hline & Monthly & $23(44.2 \%)$ & ${ }^{*} 5(35.7 \%)$ \\
\hline & Bi-monthly & $3(5.8 \%)$ & ${ }^{*} 0$ \\
\hline & Quarterly & $7(13.5 \%)$ & ${ }^{*} 1(7.1 \%)$ \\
\hline & Half-yearly & $2(3.8 \%)$ & ${ }^{*} 0$ \\
\hline & Only when necessary & $5(9.6 \%)$ & ${ }^{*} 1(7.1 \%)$ \\
\hline \multirow[t]{8}{*}{ Family Carer } & Have a family carer & ${ }^{\#} 22$ (42.3\%) & NA \\
\hline & Average length of caring & ${ }^{\# 14.7}$ years & 12.5 years \\
\hline & Relationship of carer to patient & & \\
\hline & Offspring & $6(27.3 \%)$ & $4(28.6 \%)$ \\
\hline & Spouse/partner & $14(63.6 \%)$ & $10(71.4 \%)$ \\
\hline & Other & $2(9.1 \%)$ & 0 \\
\hline & Carer receives financial assistance & $\#_{5}(22.7 \%)$ & $5(35.7 \%)$ \\
\hline & Carer receives informal support & $\# 14$ (63.6\%) & $9(64.3 \%)$ \\
\hline
\end{tabular}

$\S$ Nine carers were spouses or offspring of the patients interviewed, ${ }^{\wedge}$ One Indigenous participant was younger than 45 years old (given a gap of approximately 20 years shorter life expectancy than non-Indigenous Australian it was deemed to be appropriate to be included in the study), ${ }^{*}$ Denotes the carer's account about the patient's condition and management.

\# Denotes the patient's account about the carer.

Each interview began with a question asking the participant what it is like to live (or care for someone) with chronic illness. The interviewers asked eight consecutive questions followed by probing questions to further explore issues. The main and probing questions are summarized in Table 3.

Interviews continued to the point that sufficient data had been gathered and interviews were no longer providing new concepts. At this point it was considered that saturation had been reached and no further interviews took place. In the pilot phase of the study, issues relating to health services and health care providers were identified as key concepts in managing chronic illness. These issues were then further explored during FGDs with HCPs.

All interviews and focus group discussions were electronically recorded and transcribed using professional 
Table 2 Characteristics of health care professionals

\begin{tabular}{lll}
\hline Categories & Sub-categories & HCP (N = 63) \\
\hline Residence & ACT & $26(41 \%)$ \\
Gender & Sydney West & $37(59 \%)$ \\
& Male & $19(30 \%)$ \\
Work setting & Female & $44(70 \%)$ \\
& Hospital (in and out-patient & $22(35 \%)$ \\
& services) & \\
& Community health service & $9(14 \%)$ \\
& General practice & $22(35 \%)$ \\
& Rehabilitation centre & $4(7 \%)$ \\
Time in this employment & Policy agency & $5(8 \%)$ \\
& Less than 5 years & $18(29 \%)$ \\
E-10 years & $18(29 \%)$ \\
& More than 10 years & $27(43 \%)$ \\
& Full time & $55(87 \%)$ \\
& Part time & $8(13 \%)$ \\
\hline
\end{tabular}

transcription services. All transcripts were entered into NVivo 7, a computerized qualitative data analysis program which was used to manage the data (QSR International Pty Ltd; Doncaster, Australia). Content analysis was used to analyse and make sense of the data. The process involved analysis by topic, and each transcript was segmented by these topics into categories, constructs and domains in order to identify patterns [15]. The interviews and FGDs were managed as one dataset. In the FGDs, it was not possible to identify individual participants so we were not able to ascribe particular comments to individual HCPs or to recognise their organisation.

Data collection and analysis were carried out by the same team of researchers who checked regularly to ensure the accuracy of transcripts and consistency of the qualitative and quantitative data by comparing the interviews and the questionnaires. Field notes and memos were also used to facilitate reflexivity and the interviewers met frequently to ensure the consistency of the processes of interview, data entry, coding and interpretation of the data. Analysis revealed that the dominant themes as reported here were closely related to the concept of patient centred care.

\section{Results}

Most of the patients and care givers were older than 65 years and were not currently working. Most patients had a history of having lived with at least one chronic condition for at least ten years and most had regular contact with their general practitioners (GPs) (Table 1). We identified five major issues related to patient-centred care which limited optimal management of patients with chronic illness and their carers: poor communication with HCPs and the provision of information; poor organisation of service delivery and long waiting times to see HCPs; insufficient facilitation of self care; insufficient holistic and continuing care; and lack of patients and carers involvement in decision making (see Table 4 for details).

\section{Poor communication practice and provision of information}

Almost half of all patients and carers expressed concerns about the relevance and usefulness of the health information that they received from HCPs especially as it related to their condition(s). Participants struggled to understand the material and advice that they were given and this often led to non-compliance. One said,

A lot of the books written on diabetes are perhaps a little too sophisticated for the ordinary man-in-thestreet diabetic. It's hard for them to understand unless it's written in very simple language ...//... they say you should have a minimum of $15 \mathrm{~g}$ of carbohydrates with each meal. Well, how much is that and what is it? People don't know if it's one slice of bread or a small potato. Then the GI index...//... people think potato and rice and stuff is low GI, but it's not. (75 years old female with diabetes)

Participants suggested ways of overcoming this problem. Many indicated that they wanted materials to be written in lay language and that it should ideally be delivered interactively, e.g., shopping or cooking tours, to learn how to manage their conditions. They wanted to be actively involved in their treatment, by participating in the development of their care plans. As well, they wanted to know more about medications and the side effects that these could have. Online material that could be accessed by them, or another member of their family, would be helpful in overcoming some of these problems. They wanted to be able to access information about the most recent advances in managing their conditions. One option was to have access to training programs or similar facilities so that they could ask about their illness and its acute episodes at the time when they needed answers. For example,

They also have shopping tours with a dietitian. You've got to pay... But they go around like Woolworths [a chain supermarket] and she'll explain the labels on the things and everything. (64 years old female with diabetes)

Oh yes, I think it [interactive learning] makes a difference...It could be much more communicative, much more pleasant, much more interactive - where 
Table 3 Key and probing questions asked during interviews with patients and carers and focus group discussions with health care professionals

\section{Interviews}

Key questions

What have been the greatest challenges that you have faced as a patient OR as a carer?

\section{Probing questions}

1) Can you tell me exactly what happened? (tell me more about that), 2) Why do you think that happened? 3) How did that affect you? 4) How do you think it affected people around you? 5) How did you cope? 6) What do you think would prevent a similar thing happening again? 7) understand that may have been difficult for you, what other challenges have you faced?

What has been your experience with health professionals in terms of managing your diabetes/ $\mathrm{COPD} / \mathrm{CHF}$ OR as a carer.

What has been unhelpful about the health professionals who have provided care for you?

Apart from medical treatment and other professional health care, what else or who else helps you cope with your COPD/CHF/diabetes?

I'm interested in experiences you have had with health services in terms of managing your COPD/ CHF/diabetes. - Can you describe some of the helpful and unhelpful aspects of health services that you have received?

\section{Focus group discussions}

\section{Key questions}

What sort of problems do you face as a health professional in providing care for people with diabetes, COPD and CHF (OR: these three conditions)?

What sort of problems do you think patients and their carers face in managing their condition?

Many people are managing more than one condition at the same time and they are finding it really hard. Can you talk about that for a moment?

Patients have also told us that managing a chronic illness can cause a financial burden In all your

1) Have you ever had an interaction with a health professional that has been a problem for you? 2) What could they do that would most improve your care? 3) Who do you think should be involved in making decisions about your treatment and care?

1) Is there any help that you don't get now that you believe would assist in living with your COPD/CHF/diabetes? 2) Do you think that is something that others with your condition may also appreciate or is that something that might be more specific to your own circumstances? 3) Why is that?

1) Can you tell me exactly what happened? 2) Why do you think that happened? 3) How did that affect you/others? 4) How did you cope? 5) What do you think would prevent a similar thing happening again? 6) Can you think of anything you would change in the health service to improve this experience or even to prevent it from happening again? 7) In an ideal world, what would you want the health service to provide for people living with diabetes/COPD/CHF?

\section{Probing questions}

What do you think are the main cause(s) of those problems?

Generally speaking, people we have interviewed indicated that they struggle with managing their chronic conditions; that they find it difficult to do the 'right things' on an on-going basis. What are your thoughts on that? (Possible prompts: acting on risk factors, warning signs; identifying triggers)

We've discussed some of the challenges you and your patients face. What changes can you think of that would assist you and your patients in addressing these challenges

Given the competing demands for resources, what sorts of things should we be investing in to address the chronic disease crisis in Australia? 
Table 4 Issues related to health service encounters raised by chronically ill patients, and suggestions of patients, carers and health care professionals for overcoming them

\section{Challenges raised by participants \\ -Communication and delivery of information}

Inadequate explanation of illness, prescribed

Confusing and conflicting information provided

Practical examples of appropriate diets and concepts not provided (e.g., Glycemic Index)

Lectures given by HCPs seem pointless

No explanation given about the side effects of medication

No help provided in accessing internet

CALD participants want information in their own language

HCP seen as inflexible and

unaccommodating

Outdated information about disease management

Insufficient information about community resources provided

Poor communication by interns medication and side effects

HCP suggestions and solutions

HCPs provide patients with a written care plan in plain language

Professional organisations endorse guidelines

NS

More interactive learning experiences such as support groups

NS

NS

GPs increase their awareness of cultural issues and exercise care in providing information to CALD patients

NS

NS

Provide access to relevant data bases

Improved supervision by specialists before diagnosing conditions with a poor prognosis such as cancer

\section{-Organisation of service delivery and waiting time to see HCP's}

Arranging appointments in urgent situations

Arranging appointments when new symptoms appear

Long waiting time to make appointments and delays in seeing HCPs

Inflexible appointment times

Rigid eligibility criteria which exclude some people from inpatient or outpatient care

\section{-Facilitation of self care}

Insufficient support for self-care

On call doctors to give information and directions Electronic booking systems

Phone or SMS patients to inform them of possible delays

Greater flexibility

Revision of eligibility criteria of services to ensure they cover patients at different states of disease

NS

Handbooks and disease specific information packages

GP's and case coordinators follow up, from hospital or private health insurance

Holistic approach to patient's conditions with careful review of medical history

specialist focus only on the

-Inclusion of patients and carers in decision making

Lack of trust in patient's knowledge and understanding of signs and symptoms

Patients don't feel hopeful and motivated about the future

NS

Provide up to date information and review of the latest developments in lay language
Improvement of health literacy

Better communication between different professional groups

NS

Improved communication between patients and HCPS

Enhanced information technology infrastructure

Enhanced information technology infrastructure

Improved communication between

professionals and CALD groups

Need to improve accountability between service providers

Enhanced information technology infrastructure

Better co-ordination of care

Need to improve accountability between service providers

Need to reduce communication gaps

Enhanced electronic infrastructure

Need to reduce communication gaps

NS

Need to improve communication between various service providers

NS

Enhanced communication

Need to improve co-ordination of care by service providers

Need to improve fragmentation of services

Need to improve health literacy

Need to improve patients' focus on management of conditions

Be sure to ask patients about any tolerance or compliance issues before prescribing medications 
it's just bomb, bomb, bomb straight down the line you know and that's it. (53 year old male with diabetes)

These observations were confirmed by HCPs in all eight focus groups who also identified poor communication and information delivery as a major barrier to good health care for chronically ill patients. They linked this observation to patients' low levels of health literacy, and to conflicting and confusing messages from other HCPs, including specialists who are often busy and lack sufficient time to provide thorough information. They also suggested that patients and carers sometimes hesitated to ask questions of doctors due to doctors' time constraints, something which they recognised as a feature of the way in which health systems were organised. Some HCPs also felt that some patients experienced difficulties with communication because of confusion caused by information received from the media and the internet.

HCPs felt that health service providers needed to deliver information to patients in a more coordinated and organized manner than was currently the case in many health services.

\section{Poor organisation of service delivery and long waiting time to see HCPs}

Multiple appointments associated with chronic illness management, little flexibility in making and changing appointment times and rigid eligibility criteria for health services often led to a sense of confusion on the part of patients and a lack of follow-up by HCPs. Eighteen patients expressed confusion in following up the many appointments related to their chronic illness. A common outcome patients and carers used to address these problems was to request an ambulance to take them to hospital when in need of urgent treatment or to wait for serious episodes to evolve before seeking help. Five patients (10\%) believed that the quickest and cheapest way to get treatment was to be admitted to hospital (see Table 4).

Making appointments to see HCPs is difficult for people with chronic illnesses, but it can be especially difficult for people in paid employment. Patients also found it difficult to plan ahead and organise services well in advance of a serious episode of their condition. Often there can be a long waiting periods to schedule an appointment as well as delays in seeing the doctor at the appointment time, which can affect working time. An end result for many patients facing these barriers is often a loss of productivity and income.

But then - and that's what stops you too with going to work because these clinics are on Wednesdays. I mean you can go in during your lunchtime, but then there are other people before you so therefore you've got to take a day off to really have the time and wait..//.. you need the time off. And it's rushed. It's not the times - I work part-time, but they're not the times that I have off. (54 years old female with diabetes)

HCPs acknowledged that they had difficulties in organising services and that this sometimes resulted in delayed waiting times to see HCPs. They worried that it was difficult to connect a specialist team to patients unless there was a crisis.

\section{Insufficient facilitation of self care}

Fifteen patients and carers said that they had problems with self care and that they needed more support from the health and aged care systems than it currently provided in order to manage their chronic illness effectively. Examples given by participants to overcome this included: telephone hotlines where a HCP would be available to answer urgent questions and provide updated information about the latest progress in disease management as well as handbooks that address basic facts about each illness and its management. They also wanted to know the practical and clear boundaries and limits of their conditions so that they could manage their illness with greater confidence in their day to day life. They also expressed the need for self care support for changing their behaviours and lifestyle.

While most patients recognised that close monitoring of their condition by their GP could occasionally avoid hospital admission, they wanted to avoid having to consult their GPs every time something went wrong or their condition changed in ways that they did not understand. In contrast, those patients who had private health insurance appreciated help from their insurer in providing allied health services and treatment plans. Patients also recognised the value of close monitoring of their condition by their general practitioner. For example one said:

[My GP] tells me what the boundaries are. Tells me what the parameters are. Goes beyond, goes beyond the minimum, he's [GP] not abrupt and authoritarian and demanding. (60 years old male with CHF and diabetes)

HCPs also acknowledged the role that they played in facilitating self care of their patients. They acknowledged the discharge planner's role in facilitating self management and worried that discharge planners had become hospital bed managers. HCPs recognised the need for self management models that have been tried and tested in Australia, [13] as noted by the National Health and Hospitals Reform Commission (NHHRC) final report [16]. 


\section{Insufficient holistic and continuing care}

One of the most common challenges experienced by participants related to insufficient GP and specialist consultation time. Consultations concentrated on the immediate problem, leaving little time to discuss warning signs of emerging problems associated with the chronic illness. In response to these limitations, several patients and carers said that they wanted their HCPs to be more knowledgeable and understanding of their conditions and that the consultation not be limited to the current symptoms, but sensitive to their context. For example one said,

\section{A lot of doctors are really marred, as far as your attendance is concerned. If you go in with a sore throat, they don't care if that leg is bleeding or is falling off, you know? That's the impression you would get. But he [patient's GP] wants to know why and he's searching, you know... He looks below the surface, you know? (80 year old male with diabetes and CHF)}

HCPs also recognized the narrow focus of clinical encounters, and supported a more holistic approach to health care. They suggested that a shortage of medical practitioners meant that insufficient attention was given to co-morbidities.

Supported and holistic care is a solution to this problem. The HCPs suggested that inadequate workforce and specialisation contributed to this single illness focus of care.

\section{Lack of patients and carers involvement in decision-making}

Patients and carers were asked if they felt involved in making decisions about their condition. Seven patients and family carers reported that HCPs did not readily trust or act on their knowledge of their signs, symptoms and beliefs about their illness. This limited the capacity of patients and carers to participate in their care because there was a perception that HCPs were dismissive and failed to take the views of patients into consideration.

When they said you must wear these socks and something else, I couldn't help saying, I would be crippled if I wore them, and then what do they come up with ..//.. Why aren't I included in the talk, you know what I mean? (75 years old male with diabetes)

HCPs agreed that the inclusion of patients in planning and decision making about their health could be very helpful in achieving a better health outcome. Limited time and human resources were seen as significant barriers.

\section{Discussion}

This study has demonstrated that patients with chronic illnesses, who received care from a wide range of health services, faced a range of challenges in accessing these services and had serious concerns about their unmet needs and wants within the health system. These include poor communication with HCPs and provision of information, poor organisation of service delivery and long waiting time to see HCPs, insufficient facilitation of self care, insufficient holistic and continuing care and not involving patients and carers in decision-making. Most of these has been recognised by the NSW Severe Chronic Disease Management Program [17] and all are closely related to the key concept of patient-centred care.

These concerns feature strongly in international experience [11,18-20] and reflects experience in Australia too. We have interpreted these as relevant to the needs, wants and preferences of patients in the belief that these influence health services and the level of care that patients receive [21]. In their survey of 7505 patients, Barton et al., reported the degree to which patients' [22] wants and needs were met in general practices throughout Australia (response rate 60\%). According to their survey, $70 \%$ of participants felt that their needs and wants were met and that their care was very good or excellent [22]. In contrast, the present qualitative study demonstrated that patients and carers with chronic illnesses, who receive care from a wide range of health services, faced a range of challenges in utilizing those services and had serious concerns about their unmet needs and wants within the health system. This is consistent with the results of a qualitative study by NSW Health [23].

Given the frequent endorsement in policy rhetoric that patient centredness is a desirable attribute of a health care system that technically and humanely meets the needs of patients with chronic illness, it is reasonable to critically appraise these policies to assess whether the rhetoric translates into policy action.

The National Chronic Disease Strategy and National Service Improvement Frameworks are the current Australian national policy guides that reflect the journey of chronically ill patients from prevention to management [24]. However, they do not contain implementation plans since these have been left to State health authorities. While patient centredness has not been defined in these documents, patient needs have quite clearly been identified as the principal element in providing optimal care for chronically ill patients [25].

Currently, there are several chronic care programs running in NSW [17,26], ACT [27], and other Australian states [28-31], all of which are intended to address the challenges of caring for chronically ill patients and to assist them to better manage their conditions. According to the national strategy, these policies should contain implementation plans [24].

The NSW Chronic Care Program is the main NSW Health initiative aimed at reducing avoidable hospital 
admissions and improving quality of life for people with chronic illness and their carers [4]. Although the term patient centredness has not been mentioned in the first phase of the NSW Chronic Care Program, the concept has been introduced as the first principle of the program in its second phase [32,33]. Patient centredness has not been defined clearly in any of the program's relevant documents, but rather it has been taken to mean "placing patients at the centre of care [which] has implications for what, how, where and when care is delivered" [32]. The aim has been mentioned in order to have an impact on the health services delivered locally so that it is more responsive to local and individual patient needs [32].

As part of the Perfecting Health Care Delivery Initiative (Maggie Program) of Hunter New England Area Health Service, a qualitative study was conducted by NSW Health to investigate the concerns of patients and carers in receiving services from the health system. The main issues identified were: a) difficulties and delays in accessing services and frequent cancellation of appointments; b) poor communication from staff; c) long waiting times once patients have arrived for an appointment and overbooking of clinics; d) busy, noisy environments where staff did not seem to know what they were doing; and e) patients having to move to a number of different places to receive treatment [34]. These findings are confirmed by those of the present study. However, these have not been reflected in the NSW Chronic Care Program as performance goals. Rather, to ensure that the program remains truly patient focused, it was suggested that working parties refer continually to the question, "What is best for the patient?" [34]. This approach does not provide sufficient direction about how health systems can best address the needs and wants of patients.

Similarly, in the ACT, the first principle of the ACT Chronic Disease Strategy 2008-2011 is patient centredness [35]. It is defined as "care where people are consulted on all aspects of their care, and care is focused on the whole person, care is planned in partnership with the patient and their carers and family as agreed with the person or their advocates" [35]. While this definition is clearer than that in the NSW Chronic Care Program, it does not mention patients' wants and preferences [36]. Furthermore, there is no clear implementation plan to achieve the goal of patient centred care in the draft program which was published in 2008. Potentially, the ACT definition of patient centredness can be used for resource allocation and goal setting to a greater degree than the NSW Chronic Care Program.

Although there are examples of implemented patient centred programs in NSW [34,37], there is no strategic or business plan available on NSW Health, SWAHS or ACT Health websites which guides action in the health system. This may be due to unclear definitions of patient centredness in the chronic care programs.

Despite this gap, a number of patient centred outcomes have been used as measures to identify the successful implementation of strategies to evaluate various models of care in NSW [38]. These include improved documentation of patient encounters, reduced numbers of falls and medication errors, reduced numbers of re-presentations to emergency departments and re-admissions, increased numbers of attendance at health promotion activities and primary health care facilities, improvements in a range of mental health outcomes and generic measures of improvements such as reduced numbers of complaints and critical incidents [38]. Each of these factors is considered to be an essential ingredient of a health system that is focused on the overall health and well-being of patients. Interestingly, patients' needs, wants and preferences are missing from the list.

Access to holistic patient centred care with consumers as partners has been identified as one of many frequently raised issues and suggestions to reform primary health care by community groups in the recent NHHRC final report [16]. At a state level, the concept of patientcentredness has also been identified by the Special Commission of Inquiry into Acute Care Services in NSW Public Hospitals as an essential ingredient in the reform of the NSW hospital system [39]. The report says that effective care for people with chronic illness must be based on the needs of patients rather than on the management of specific medical conditions, an approach that has been confirmed by the people we spoke to during the course of this study.

The authors of this paper consider that answering the question, "What is best for the patient?" [34] will not be sufficient to achieve a patient centred health system which is the first principle of both NSW and ACT chronic care programs $[33,35,40]$. Instead, we argue in this paper that needs, wants and preferences of patients and carers should be found and addressed in the chronic care programs.

As this paper has shown, patient centredness has been placed rhetorically at the centre of national and NSW chronic disease programs. However, there is neither a clear definition of patient centredness nor are there clear performance goals, implementation plan, and evaluation criteria in place. Findings from this study have confirmed the importance of integrating the needs and wants of patients into chronic care programs. As HCPs have indicated, close attention can be paid to these needs and wants of patients by improving patient health literacy, improving communication with HCPs, enhancing access to information technology and addressing other communication related issues. 
This study has clearly identified what patients and carers want from the health system and these are similar to those identified by NSW Health [34]. These can be used to set up strategies and implementation plans with key performance areas to achieve patient centredness. These must then be translated into health system redesign features to address the unmet goal of the NSW Chronic Care Program. Ideally, this needs to be replicated in ACT and across Australia.

The finding of this study may be limited by the fact that they are based on interviews conducted in two specific locations in Australia and as a result, they may not be generalisable to other locations. The transcriber was unable to identify individual HCPs so it was not possible to ascribe comments to specific people or to recognise their organisation.

\section{Conclusion}

Although patient centredness is the main stated principle of national, ACT and NSW chronic care programs, it has not been clearly defined and there is no subsequent strategic or business plan in any of these jurisdictions that takes the principle and turns it into actions that can be easily implemented. Furthermore, no specific resources have been allocated to the goal of achieving patient centredness.

If patient centredness is to have meaning as a principle within policies for the care of chronically ill patients, it must first be clearly defined. Second, the detail of patient centredness for various patient conditions must be analysed in sufficient depth to enable necessary and relevant actions to be defined. Finally, this process will allow those actions to be examined in the context of institutional and community based clinical practice, accountability, financing and management with this having the potential to contribute significantly in overcoming challenges posed by chronic illness.

\section{Endnote}

${ }^{\text {a }}$ Pharmacists were recruited to the larger study but they have been excluded from this analysis because of the focus on patient experience with health services and health care professionals.

\section{Competing interests}

The authors declare that they have no competing interests.

\section{Authors' contributions}

MM led the drafting of the manuscript. CA made a substantial contribution to the writing of the paper. MM, Y-HJ, BE designed and implemented the qualitative study, and participated in the recruitment, interviewing and analysis of data. SRL, PD and TU participated in the design of the main study (SCIPPS) and supervised the qualitative study. All authors contributed to the writing and review of the manuscript and all authors have approved the final manuscript.

\section{Acknowledgments}

The authors acknowledge the patients, carers and HCPs who participated in this study. Thanks to SWAHS and ACT Health staff for their collaboration and assistance in recruiting participants, thanks also to all members of the SCIPPS team.

\section{Source of funding}

The Serious and Continuing IIInesses Policy and Practice Study (SCIPPS) is a National Health and Medical Council of Australia (NHMRC) funded program (no: 402793) conducted at the University of Sydney and The Australian National University and administered by the Menzies Centre for Health Policy.

\section{Author details}

${ }^{1}$ Yazd Cardiovascular Research Centre, Shahid Sadoughi University of Medical Sciences, Yazd, Iran. ${ }^{2}$ Menzies Centre for Health Policy, University of Sydney, Sydney, Australia. 'Sydney Nursing School, University of Sydney, Sydney, Australia. ${ }^{4}$ Centre for Health Stewardship, College of Medicine and Health Sciences, Australian National University, Canberra, Australia. ${ }^{5}$ Discipline of General Practice, University of Sydney, Sydney, Australia. ${ }^{6}$ The George

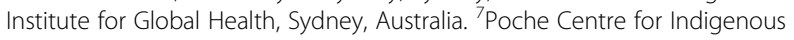
Health, University of Sydney, Sydney, Australia.

Received: 22 May 2012 Accepted: 28 June 2013

Published: 3 July 2013

\section{References}

1. AlHW: Health system expenditure on disease and injury in Australia, 2000-01. Canberra: Australian Institute of Health and Welfare; 2004. www.aihw.gov. au/WorkArea/DownloadAsset.aspx?id=6442457385 (accessed 26.06.2011).

2. Begg S, Vos T, Barker B, Stevenson C, Stanley L, Lopez A: The burden of disease and injury in Australia 2003. Canberra; 2007. www.aihw.gov.au/ WorkArea/DownloadAsset.aspx?id=6442459747 (accessed 06.07.2011).

3. Tobias M, Taylor R, Yeh LC, Huang K, Mann S, Sharpe N: Did it fall or was it pushed? The contribution of trends in established risk factors to the decline in premature coronary heart disease mortality in New Zealand. Aust N Z J Public Health 2008, 32:117-125.

4. NSWHealth: Improving health care for people with chronic illness - A blueprint for change 2001-2003. Sydney: New South Wales Health; 2001. http://www0. health.nsw.gov.au/pubs/2001/pdf/chronic.pdf (accessed 01.12.2011).

5. Wagner EH: More than a case manager. Ann Intern Med 1998, 129:654-656.

6. Wagner EH, Austin BT, Davis C, Hindmarsh M, Schaefer J, Bonomi A: Improving chronic illness care: translating evidence into action. Health Aff 2001, 20:64-78.

7. Wagner EH, Bennett SM, Austin BT, Greene SM, Schaefer JK, Vonkorff M: Finding common ground: patient-centeredness and evidence-based chronic illness care. J Altern Complement Med 2005, 11(Suppl 1):S7-S15.

8. Stewart M, Brown JB, Donner A, McWhinney IR, Oates J, Weston WW, Jordan J: The impact of patient-centered care on outcomes. J Fam Pract 2000, 49:796-804.

9. Stewart M: Towards a global definition of patient centred care. BMJ 2001, 322:444-445.

10. Little P, Everitt H, Williamson I, Warner G, Moore M, Gould C, Ferrier K, Payne $S$ : Observational study of effect of patient centredness and positive approach on outcomes of general practice consultations. BMJ 2001, 323:908-911.

11. Coulter A, Ellins J: Effectiveness of strategies for informing, educating, and involving patients. BMJ 2007, 335:24-27.

12. Jeon Y-H, Jowsey T, Yen L, Glasgow N, Essue B, Kljakovic M, Mirzaei M: Achieving a balanced life in the face of chronic illness. Aust J Prim Health 2010, 16:66-74.

13. Yen L, Gillespie J, Jeon Y-H, Kljakovic M, Brien J, Pearce-Brown C, Jan S, Lehnbohm E, Usherwood T: Health professionals, patients and chronic illness policy: a qualitative study. Health Expect 2010, 14:10-20.

14. Devlin N, Hansen P, Herbison P, Macran S: A "new and improved" EQ-5D valuation questionnaire? Results from a pilot study. Eur J Health Econ 2005, 6:73-82.

15. Morse JM, Field P-A: Qualitative research methods for health professionals. Thousand Oaks: Sage Publications; 1995.

16. NHHRC: A Healthier Future For All Australians - Final Report of the National Health and Hospitals Reform Commission - June 2009. Canberra: National 
Health and Hospitals Reform Commission; 2009. http://www.health.gov.au/ internet/nhhrc/publishing.nsf/Content/nhhrc-report (accessed 17.02.2011).

17. NSWHealth: Severe Chronic Disease Management Program. 2010. http://www. health.nsw.gov.au/cdm/severe_chronic_disease_management_program.asp (accessed 24.09.2011).

18. Bodenheimer T: Coordinating care-a perilous journey through the health care system. N Engl J Med 2008, 358:1064-1071.

19. Lawton J, Parry O, Peel E, Douglas M: Diabetes service provision: a qualitative study of newly diagnosed Type 2 diabetes patients' experiences and views. Diabet Med 2005, 22:1246-1251.

20. Pattenden JF, Roberts H, Lewin RJ: Living with heart failure; patient and carer perspectives. Eur J Cardiovasc Nurs 2007, 6:273-279.

21. Cleary PD, Edgman-Levitan S, Roberts M, Moloney TW, McMullen W, Walke $J D$, Delbanco TL: Patients evaluate their hospital care: a national survey. Health Aff (Millwood) 1991, 10:254-267.

22. Barton CA, Proudfoot J, Powell-Davies G, Holton C: How Patient-centred is Australian General Practice?. Helath Issues Centre; 2005. www.healthissuescentre.org.au/documents/items/2008/05/206514-upload00001.pdf (accessed 21.02.2011)

23. McDonald B, Swan J, Considine R: Evaluation of The Maggie Program: A Journey in Health Services Improvement (Executive Summary). Hunter New England Area Health Services; 2006. http://www.health.vic.gov.au/archive/ archive2011/improvingcareforums/0506/maggieprogram.pdf (accessed 12.01.2011)

24. NHPAC: National Chronic Disease Strategy. Canberra: National Health Priority Action Council- Australian Government Department of Health and Ageing; 2005. http://www.health.gov.au/internet/main/publishing.nsf/Content/pqncds-strat (accessed 17.08.2011).

25. NHPAC: National Service Improvement Framework for Diabetes. Adelaide, SA National Health Priority Action Council; 2005. http://www.health.sa.gov.au/ DesktopModules/SSSA_Documents/LinkClick.aspx?tabid=84\&mid=513\&table= SSSA Documents\&field=ItemID\&id=140\&link=H\%3A\%5CUploads $\%$ 5CConsultation-Draft-Diabetes-NSIF-May-2005.pdf (accessed 12.02.2011).

26. NSWHealth: NSW Chronic Care Program. 2007. http://www.health.nsw.gov. au/health_pr/chronic_care/ (accessed 03.10.2011).

27. ACTHealth: Health Services - Chronic Care Program. Canberra: ACT Health, 2008. http://health.act.gov.au/health-services/chronic-disease-management/ services/chronic-care-program/chronic-care-program (accessed 12.11.2011).

28. VictoriaHealth: HARP - Chronic disease managment. Melbourne: Victoria Health; 2008. www.health.vic.gov.au/harp/downloads/harp_cdm_guidelines. pdf (accessed 22.11.2011).

29. QLDHealth: Queensland Strategy for Chronic Disease 2005-2015. Brisbane: Queensland Health; 2005. www.health.qld.gov.au/chronicdisease/ documents/strat2005to15 full.pdf (accessed 21.01.2011).

30. SADHS: Chronic disease : prevention \& management opportunities for South Australia 2003. Adeleide: South Australia Department of Human Services (Primary Health Care Branch); 2004. http://www.sapo.org.au/binary/ binary1883/Chronic.pdf (accessed 21.01.2011).

31. TDHHS: Strengthening the prevention and management of chronic conditions: policy framework 2005. Hobart- Tasmania: Tasmania: Department of Health and Human Services; 2005.

32. NSWHealth: NSW Chronic Care Program: Phase Two 2003-2006. Strengthening health care for people with chronic illness. Sydney: NSW Department of Health; 2004:6-34. http://www.health.nsw.gov.au/pubs/2005/pdf/ chronic_care2.pdf (accessed 12.11.2011).

33. NSWHealth: NSW Chronic Care Program Phase Three: 2006-2009, NSW Chronic Disease Strategy. Sydney: NSW Department of Health; 2006. http://www.health.nsw.gov.au/pubs/2006/chroniccare_3.html (accessed 12.01.2011).

34. HNE-AHS: The Maggie Program - It's time for a better system. Hunter New England Area Health Services; 2004:2. www.hnehealth.nsw.gov.au/_data/ assets/pdf_file/0020/35732/Maggie_ambulatory_care_summary.pdf (accessed 12.01.2011).

35. ACTHealth: ACT Chronic Disease Strategy. Canberra: ACT Health; 2008:14. www.health.act.gov.au/c/health?a=dlpol\&policy=1190165949 (accessed 12.11.2011).

36. Bauman AE, Fardy HJ, Harris PG: Getting it right: why bother with patientcentred care? Med J Aust 2003, 179:253-256.

37. SWAHS: Sydney West Area Health Service Healthcare Services Plan 2005 2010. Sydney 2005. www.docstoc.com/.//Sydney-West-Area-HealthcareServices-Plan-CAREFirst-Strategic-Health (accessed 12.02.2011).
38. NSWHealth: First report on the models of care project. Sydney: NSW Health; 2006. http://www.health.nsw.gov.au/pubs/2006/models_of_care.html (accessed 12.02.2011).

39. Garling P: Final Report of the Special Commission of Inquiry into Acute Care Services in NSW Public Hospitals. Sydney: NSW Health; 2008. www.dpc.nsw. gov.au/_.../Overview___Special_Commission_Of_Inquiry_Into_Acute_ Care_Services_In_New_South_Wales_Public_Hospitals.pdf (accessed 20.03.2011).

40. NSWHealth: NSW Chronic Care Program 2000-2003: Strengthening capacity for chronic care in the NSW health system. Report on Phase one. Sydney; 2004. http://www.health.nsw.gov.au/pubs/2004/pdf/chroniccare2003.pdf (accessed 01.12.2011).

doi:10.1186/1472-6963-13-251

Cite this article as: Mirzaei et al:: A patient-centred approach to health service delivery: improving health outcomes for people with chronic illness. BMC Health Services Research 2013 13:251.

\section{Submit your next manuscript to BioMed Central and take full advantage of:}

- Convenient online submission

- Thorough peer review

- No space constraints or color figure charges

- Immediate publication on acceptance

- Inclusion in PubMed, CAS, Scopus and Google Scholar

- Research which is freely available for redistribution

Submit your manuscript at www.biomedcentral.com/submit
Ciomed Central 